\title{
Testing the impact attenuation of loose-fill playground surfaces
}

\author{
Mick G Mack, Jeffrey J Sacks, Donna Thompson
}

\begin{abstract}
Objectives-Our objective was to measure the impact attenuation performance of five types of loose-fill playground surfaces at a variety of drop heights, material depths, and conditions.

Methods-In a laboratory setting, an instrumented head form was dropped on varying depths of loose-fill materials at one foot height increments until critical deceleration values were exceeded. The effects of test box size, material temperature, and compression were also studied. Results-Data suggest that a larger test box size influences test results. Uncompressed materials performed quite unexpectedly, that is, resilience did not necessarily increase with increasing depth of material and temperature did not have uniform effects. Compression before testing improved consistency of results.

Conclusion-The current standard test procedure (ASTM F1292) appears problematic for loose-fill materials. Our results indicate that (1) shredded rubber was the best performer; (2) there was little difference between sand, wood fibers, and wood chips; and (3) pea gravel had the worst performance, making it a poor choice for playground surfacing.

(Injury Prevention 2000;6:141-144)
\end{abstract}

Keywords: playgrounds; impact attenuation; surfacing

National Program for Playground Safety, University of Northern Iowa, Cedar Falls, Iowa

M G Mack

D Thompson

Division of

Unintentional Injury

Prevention, National

Center for Injury

Prevention and

Control, US

Department of Health

and Human Services,

US Public Health

Service, Centers for

Disease Control and

Prevention, Atlanta,

Georgia

J J Sacks

Correspondence to: Dr Mick G Mack, National Program for Playground Safety, University of Northern Iowa-WRC 203, Cedar Falls, Iowa

50614-0618, USA (e-mail:

playground-safety@uni.edu) falls below the critical height are not likely to produce life threatening, serious head injuries, while those above that height may. To deter- mine critical height, an instrumented head form is dropped from a known height onto a surface of known depth, and deceleration is measured. If the resulting deceleration is less than 1000 for the head injury criterion (HIC) ${ }^{5}$ and 200 for g-max, ${ }^{5}$ then the height is deemed safe and the drop height is increased one foot for the next test. The last one foot height at which the HIC and g-max values stay below the specified limits is termed the critical height.

Test results are readily available from manufacturers of playground surface materials, such as rubber mats; however, because many loosefill materials are generally sold for purposes other than playground surfacing, the shock absorbing properties of these materials are rarely provided. The US Consumer Product Safety Commission's (CPSC) impact absorption tests of loose-fill materials provide the only data on critical heights of some loose-fill materials. ${ }^{67}$ Concerned with risk management and safety, many playground managers select surfaces on the basis of these test results.

Research suggests that test results may be influenced by size of the test box, temperature, and compression of the material, ${ }^{68}$ but these issues have not been systematically quantified. ASTM F1292 specifies that a box with a minimum inside dimension of $18 \times 18$ inches be used. ASTM F1292 also specifies that samples are to be temperature conditioned a minimum of four hours and testing must be started within one minute of taking a sample out of the temperature setting chamber; tests are to be conducted at $30^{\circ}, 72^{\circ}$, and $120^{\circ} \mathrm{F}\left(-1^{\circ}, 23^{\circ}\right.$, and $49^{\circ} \mathrm{C}$ ). Because of the size and weight of loose-fill aggregates, it is physically impossible to set up and begin testing within one minute of taking the sample out of the conditioning chamber. ${ }^{68}$ Additionally, if conditioned for only four hours, materials do not always maintain the appropriate temperature throughout the testing procedure. Thus, material temperatures during tests may not be what were intended. Finally, ASTM F1292 makes no specification regarding compression, a condition likely to be seen in real world use of these materials.

Accordingly, the goal of this study was to systematically examine impact attenuation performance of loose-fill playground surfaces at a variety of drop heights and material depths, and ascertain the effects of box size, temperature, and compression.

\section{Methods}

MATERIAL SELECTION

Five loose-fill materials in common use for playgrounds were selected: sand, pea gravel, wood chips, engineered wood fibers, and 
shredded rubber. We used ASTM standards for material selection whenever possible. ${ }^{8}$

ASTM C897 plaster sand ${ }^{9}$ was selected because of its availability and because its coarseness lies between the fine and coarse sand described in the CPSC handbook. ${ }^{7}$ Consumers find it difficult to follow CPSC guidelines because there is no standard definition of pea gravel. ${ }^{6}$ Accordingly, because larger particles may cause more serious injuries if thrown by children, it is recommended that aggregates no greater than $3 / 8$ inches be used on playgrounds. ASTM C33 concrete aggregates ${ }^{10}$ is the only ASTM gravel specification that meets this requirement. Unfortunately, aggregates meeting the ASTM C33 standard are not readily available across the US; however, a uniform $3 / 8$ inch gravel is consistently available. Therefore, rounded gravel particles not greater than $3 / 8$ inches maximum or nominal size which were washed, free of dust, clay, dirt, or foreign objects was selected as sample material. ASTM also does not provide a standard for wood chips; consequently, the sample specifications followed the CPSC handbook description ${ }^{7}$ - that is, it consisted of random sized wood chips, twigs, and leaves collected from a wood chipper being fed tree limbs, branches, and brush. The sample was shredded at least two weeks before the testing date. ASTM standards are not available for engineered wood fiber, so this manufactured product consisted of random sized engineered wood fibers from recognized hardwoods, as described in the CPSC handbook. ${ }^{7}$ There is also no ASTM standard for shredded rubber; the sample consisted of \#10 mesh crumb shredded rubber particles from recycled materials.

\section{TEST EQUIPMENT}

All impact attenuation tests were conducted by Detroit Testing Laboratory, an independent laboratory accredited by the American Association for Laboratory Accreditation to International Standards Organization/International Electrotechnical Commission guide 25 requirements. Test equipment consisted of: (a) 12 foot Detroit Testing Laboratory impact tower; (b) KIA metal headform for procedure C, test method F355; (c) KME, HIC computer IV, M/N 300 series; (d) Piezotronics, acceler-

Table 1 Average head injury criterion (HIC) and g-max values for 6 inches of shredded rubber at ambient temperature by box size and drop height

\begin{tabular}{|c|c|c|c|c|c|c|}
\hline \multirow{2}{*}{$\begin{array}{l}\text { Drop } \\
\text { height } \\
\text { (feet) }\end{array}$} & \multicolumn{3}{|l|}{$H I C$} & \multicolumn{3}{|l|}{$g-\max$} \\
\hline & $18 \times 18$ & $18 \times 36$ & $\%$ Difference & $18 \times 18$ & $18 \times 36$ & $\%$ Difference \\
\hline 1 & 8.7 & 9.4 & 0.1 & 15.7 & 15.4 & -1.9 \\
\hline 2 & 31.6 & 30.2 & -4.4 & 26.6 & 25.4 & -4.5 \\
\hline 3 & 71.6 & 53.4 & -25.4 & 39.3 & 32.6 & -17.0 \\
\hline 4 & 118.6 & 88.8 & -25.1 & 49.9 & 41.4 & -17.0 \\
\hline 5 & 182.0 & 145.1 & -20.3 & 61.4 & 53.0 & -13.7 \\
\hline 6 & 241.6 & 227.8 & -5.7 & 70.9 & 66.4 & -6.3 \\
\hline 7 & 325.7 & 288.5 & -11.4 & 82.3 & 73.6 & -10.6 \\
\hline 8 & 394.7 & 382.7 & -3.0 & 90.5 & 85.1 & -6.0 \\
\hline 9 & 548.6 & 426.2 & -22.3 & 108.3 & 89.6 & -17.3 \\
\hline 10 & 674.5 & 585.1 & -13.3 & 120.7 & 106.8 & -11.5 \\
\hline 11 & 820.6 & 711.8 & -13.3 & 134.1 & 119.8 & -10.7 \\
\hline 12 & 1117.0 & 917.1 & -17.9 & 158.8 & 139.1 & -12.4 \\
\hline \multicolumn{3}{|c|}{ Mean difference } & -13.5 & & & -10.7 \\
\hline
\end{tabular}

ometer, M/N 353B17; (e) GSE, load cell, M/N 5353-2K; and (f) Daytronic, strain gauge indicator, M/N 3170. Equipment was calibrated according to American National Standards Institute/National Conference of Standard Laboratories Z540-1-1994.

\section{TEST PROCEDURES}

All tests met the specifications of ASTM F1292-95, ${ }^{11}$ with modifications as noted below. The test procedure required the head form to impact the material in the center of the box. After conditioning a sample for at least four hours before testing (to bring to the desired temperature), two thermocouples were placed in the sample, at approximately two inches and midway deep to verify maintenance of proper temperature throughout the test. If temperatures varied $\pm 2^{\circ} \mathrm{F}$ beyond specified, the test was aborted and completely repeated. The initial drop height was one foot and was increased in one foot intervals until the critical height was reached, that is, until HIC value exceeded 1000 or g-max exceeded 200 or 12 feet was reached (the maximum height of the Detroit Testing Laboratory impact tower). HIC and g-max values were calculated based on the average of the second and third drops at each height. ${ }^{11}$

Stage 1-effect of box size

Tests were conducted using a box with interior dimensions of $18 \times 18$ inches and a box with interior dimensions of $18 \times 36$ inches. The test material was 6 inches of shredded rubber.

\section{Stage 2-effect of depth and temperature}

Each of the five samples were tested at depths of $3,6,9$, and 12 inches at three temperatures $\left(30^{\circ}, 72^{\circ}\right.$, and $\left.120^{\circ} \mathrm{F}\right)$.

\section{Stage 3-effect of compression}

The sample box was filled to the required depth. A machine loaded the top of the sample with a plate to $1.125 \mathrm{lb}$ per square inch (729 lb). We chose this load because we felt it represented the compression produced by a 95th percentile 12 year old (the upper age for which public playground equipment is designed). Drop height was measured from the compacted depth.

\section{Results}

Stage 1-effect of box size

Head injury criterion values for 6 inches of shredded rubber tested at ambient temperature were an average of $14 \%$ lower for the $18 \times 36$ inch box than the $18 \times 18$ inch box (table 1 ). Decreases in HIC values ranged from $0 \%$ to $25 \%$. Similarly, the $18 \times 36$ inch box resulted in an $11 \%$ average reduction of g-max compared with the $18 \times 18$ inch box; decreases in g-max ranged from $2 \%$ to $17 \%$. The $18 \times 36$ inch box was used for all subsequent tests because box size influenced the impact attenuation test results and because the larger box size was thought to better represent actual playground conditions. 
Table 2 Critical heights in feet for loose-fill materials, by compression status, Fahrenheit temperature, and material depth

\begin{tabular}{|c|c|c|c|c|c|c|c|c|c|c|c|c|c|c|c|}
\hline \multirow{2}{*}{$\begin{array}{l}\text { Depth (inches) } \\
\text { and } \\
\text { compression } \\
\text { status }\end{array}$} & \multicolumn{3}{|c|}{ Gravel } & \multicolumn{3}{|c|}{ Sand } & \multicolumn{3}{|c|}{ Wood chips } & \multicolumn{3}{|c|}{ Wood fibers } & \multicolumn{3}{|c|}{ Rubber } \\
\hline & $30^{\circ}$ & $72^{\circ}$ & $120^{\circ}$ & $30^{\circ}$ & $72^{\circ}$ & $120^{\circ}$ & $30^{\circ}$ & $72^{\circ}$ & $120^{\circ}$ & $30^{\circ}$ & $72^{\circ}$ & $120^{\circ}$ & $30^{\circ}$ & $72^{\circ}$ & $120^{\circ}$ \\
\hline \multicolumn{16}{|l|}{ Uncompressed } \\
\hline 3 & 4 & 3 & 5 & 7 & 6 & 6 & 4 & 4 & 4 & 5 & 5 & 4 & 4 & 3 & 4 \\
\hline 6 & 8 & 6 & 7 & 12 & 10 & 9 & 8 & 8 & 6 & 9 & 10 & 8 & 12 & 12 & 12 \\
\hline 9 & 6 & 5 & 8 & 11 & 10 & 12 & 10 & 11 & 9 & 12 & 12 & 10 & 12 & 12 & 12 \\
\hline 12 & 9 & 5 & 8 & 12 & 8 & 10 & 12 & 12 & 12 & 12 & 12 & 12 & 12 & 12 & 12 \\
\hline \multicolumn{16}{|l|}{ Compressed } \\
\hline 3 & 5 & 5 & 4 & 7 & 6 & 6 & 4 & 4 & 4 & 4 & 4 & 4 & 4 & 5 & 3 \\
\hline 6 & 4 & 4 & 4 & 8 & 12 & 10 & 8 & 6 & 6 & 8 & 7 & 7 & 12 & 12 & 12 \\
\hline 9 & 8 & 6 & 5 & 10 & 12 & 10 & 10 & 9 & 8 & 11 & 9 & 10 & 12 & 12 & 12 \\
\hline 12 & 9 & 8 & 6 & 12 & 11 & 12 & 12 & 12 & 12 & 12 & 12 & 12 & 12 & 12 & 12 \\
\hline
\end{tabular}

Stage 2-effect of depth and temperature on uncompressed materials

Uncompressed materials behaved idiosyncratically and inconsistently. For sand and gravel, there were considerable differences between the values of HIC and g-max for the three drops, while wood chips, wood fibers, and shredded rubber were more consistent. For gravel, the reading for the second drop at each height was always higher than the first (an increase of $150 \%$ to $200 \%$ was not uncommon). However, the third drop was often less than the second. There were also differences between the first and second drop values for sand. Temperature and depth influenced these differences. At $30^{\circ} \mathrm{F}$ and $120^{\circ} \mathrm{F}$, the readings for the second and third drops were similar. However, at $72^{\circ} \mathrm{F}$ the differences appeared related to depth. For drop heights over 2 feet, the 6 inch and 9 inch depths recorded a third drop that was always lower than the second. Conversely, at 12 inches the second value was always lower (data available upon request).

Critical drop heights did not necessarily increase with increasing depths of material, and temperature did not have a uniform effect within a material (table 2). For gravel and sand, as the depth increased, critical height did not consistently increase, as would be expected. Ambient conditions resulted in the lowest critical heights for all depths of gravel. Extreme temperatures tended to improve both sand and gravel impact attenuation. For sand, it is noted that increasing temperature resulted in lowered critical heights at 6 inches but not at a 9 inch or 12 inch depth.

The critical height for wood chips increased as the depth increased at all three temperatures. The effectiveness of wood chips decreased slightly at $120^{\circ} \mathrm{F}$ for the 6 inch and 9 inch depths. However, these differences were not as evident at 12 inches. Like wood chips, critical heights of engineered wood fibers increased as the material depth increased. Again there were slight differences for the $120^{\circ} \mathrm{F}$ condition that were not evident at 12 inches. Uncompressed shredded rubber displayed excellent impact attenuation characteristics. The 6, 9, and 12 inch depths all had a critical height of 12 feet and were not significantly affected by temperature. Data (not shown) indicated that impact attenuation increased as the depth of material increasedfor example, for a drop height of 12 feet under ambient conditions, 6 inch depth values were
HIC $=917$ and $g-\max =139 ; 12$ inch values were $\mathrm{HIC}=190$ and $\mathrm{g}-\max =48$.

\section{Stage 3-effect of compression}

Most materials displayed little compaction ( $<0.5$ inches) at the 3, 6, and 9 inch depths. However, at the 12 inch depth, gravel and sand maintained a compaction near 0.5 inches, while wood chips, wood fibers, and shredded rubber showed much more compaction with maximum readings of 2.5 inches, 2 inches, and 1.875 inches respectively.

HIC and g-max values for compressed materials revealed second and third drop readings that were fairly consistent. Again, sand and gravel displayed the greatest variability.

When compressed, the impact attenuation characteristics of these five loose-fill materials suggested that increases in surface depth corresponded with increases in critical height for all test conditions except 6 inches of gravel and 12 inches of sand (table 2). The discrepancy for 12 inches of sand at $72^{\circ} \mathrm{F}$ could be the result of an outlier, because the second drop was $98 \%$ higher than the first and $63 \%$ higher than the third $(129,254$, and 155 g-max, respectively). In general, wood fiber, gravel, and wood chips performed better at cooler temperatures while sand performed slightly better under ambient conditions. Impact attenuation for shredded rubber improved as depth increased, with HIC values decreasing from 829 to 190 and g-max decreasing from 131 to 47 (6 inch and 12 inch depth respectively). By comparison, 12 inches of other materials with a critical height of 12 feet resulted in values considerably higher (shredded rubber: 190, 47; wood fibers: 738, 119; wood chips: 754,119 ; and sand: 788,192 ; HIC and g-max respectively).

\section{Discussion}

Our results suggest that the current standard ${ }^{11}$ used to test impact attenuation characteristics of loose-fill materials for playground surfaces may produce unreliable (and possibly invalid) results. In considering our results, it is important to keep in mind three main limitations of this work. First, we explored test box size effects for only one material at one temperature and one depth. Second, our load compaction may not accurately simulate the effect of many children playing on a playground surface over a long period. Third, 
because of the expense, we did not go beyond the minimum tests specified in ASTM F1292 - that is, we did only three drops at each height and material depth. Nevertheless, potential users of these materials for playgrounds need to be extremely cautious when interpreting test results for uncompressed loose-fill surface materials. While some materials had fairly consistent readings, uncompressed gravel and sand produced erratic results. Data indicating that a 6 inch depth of sand or gravel has better resilience (that is, a higher critical height) than a 12 inch depth are counterintuitive. While this test result may be due to chance, it suggests that the current test methodology may be problematic for loose-fill materials in that it can produce such findings.

A likely explanation is that critical heights are based on the average of the second and third drop. During our tests, uncompressed gravel readings for the second drop at each height were always considerably higher than the first (an increase of $150 \%$ to $200 \%$ was not uncommon), indicating that the surface may have been displaced or compressed by the first drop. However, the third drop was often less than the second, which suggests that the displaced material fell back into the indentation before the third drop. Uncompressed sand showed erratic and unpredictable values based on the average of the second and third drops, as well as an effect of temperature and depth. These drop specific differences for sand and gravel raise questions about how these materials perform on an actual playground. Averaging additional drops might provide more representative test results for these materials. ${ }^{6}$ For wood fibers, wood chips, and shredded rubber, averaging the second and third drops appeared appropriate and representative.

We found differences between uncompressed and compressed samples in consistency of results and critical heights. The compressed state showed a fairly orderly increase in critical height as material depth increased. The compressed/uncompressed differences were particularly evident for sand and gravel-that is, 10 of 24 tests showed better critical heights for compressed surfaces. Perhaps, compression reduces the amount of displacement that occurs between the three drops. Further testing and study is necessary to see if compression provides a better representation of loose-fill material performance in actual playground conditions.

Our critical height results are discrepant with the CPSC's results, ${ }^{2}$ evidencing differences of one to greater than three feet (table 3). For example, the CPSC lists 5 feet as the critical height for 9 inches of uncompressed sand (both fine and coarse), while this study obtained a critical height of 10 feet-twice as high. Although we only tested the effect of box size with one material at one temperature and one depth, our research and that of others ${ }^{6}$ suggests that our use of an $18 \times 36$ inch box
Table 3 Critical drop heights in feet for uncompressed materials, by source and material depth

\begin{tabular}{llllll}
\hline $\begin{array}{l}\text { Depth } \\
\text { (inches) }\end{array}$ & Source & Gravel & Sand & $\begin{array}{l}\text { Wood } \\
\text { chips }\end{array}$ & $\begin{array}{l}\text { Wood } \\
\text { fibers }\end{array}$ \\
\hline 6 & CPSC $^{2}$ & 6 & 5 & 7 & 6 \\
& This study $^{2}$ & 6 & 10 & 8 & 8 \\
9 & CPSC $^{2}$ & 7 & 5 & 10 & 7 \\
\multirow{4}{*}{12} & This study $^{2}$ & 5 & 10 & 11 & 10 \\
& CPSC $^{2}$ & 10 & $6-9$ & 11 & $>12$ \\
& This study & 5 & 8 & 12 & 12 \\
\hline
\end{tabular}

CPSC $=$ Consumer Product Safety Commission.

may explain some of these differences, as its use results in higher critical heights. We believe that a larger box better simulates actual playground conditions. However, the effects of box size need further exploration, as does a comparison of laboratory tests to real field conditions.

\section{Implications for prevention}

Our results suggest a need to improve the ASTM F1292 standard for loose-fill materials. ${ }^{511}$ Variables to consider include modifying the box size, better controlling temperature conditions, adding a compression component, and performing more drops to average the results. In the meantime, although consumers need to exhibit caution in overreliance on test results, our results indicate that the performance of shredded rubber was clearly superior, and that there was little performance difference between sand, wood fibers, and wood chips. Pea gravel had the worst impact attenuation performance; compared with other available loose-fill materials, we believe pea gravel is a relatively poor choice as a safe playground surface and should not be used under equipment over 6 feet tall. This publication was supported by grant number U17/
CCU712119-02 from the Centers for Disease Control and Prevention (CDC).

1 Mack MG, Hudson S, Thompson D. A descriptive analysis of children's playground injuries in the United States 1990-4. Inj Prev 1997;3:100-3.

2 Consumer Product Safety Commission. Handbook for public playground safety. Washington, DC: US Government Printing Office, 1997.

3 Chalmers, D J, Marshall SW, Langley JD, et al. Height and urfacing as risk factors for injury in falls from playground equipment: a case-control study. Inj Prev 1996;2:98-104.

4 Centers for Disease Control and Prevention. Playground safety-United States, 1998-1999. MMWR Morb Mortal Wkly Rep 1999;48(16):329-32.

5 American Society for Testing and Materials. Standard specification for impact attenuation of surface systems under and around playground equipment, F1292-91. Philadelphia, PA: ASTM, 1991.

6 Ramsey LF, Preston JD. Impact attenuation performance of playground surfacing materials. Washington, DC: US Conplayground surfacing materials. Washington,

7 Consumer Product Safety Commission. Handbook for public playground safety. Washington, DC: US Government Printing Office, 1991 .

8 Moore Iacofano and Goltsman Inc. Criteria search and analysis report on children's outdoor play areas. Berkeley, CA: Moore Iacofano and Goltsman Inc, 1993.

9 American Society for Testing and Materials. Standard specification for aggregate for job-mixed Portland cement-based plasters, C897-88. Philadelphia, PA: ASTM, 1988.

10 American Society for Testing and Materials. Standard specification for concrete aggregates, C33-93. Philadelphia, PA: ASTM, 1993.

11 American Society for Testing and Materials. Standard specification for impact attenuation of surface systems under and around playground equipment, F1292-95. West Conshohocken, PA: ASTM, 1995. 